\title{
HETEROCHROMATIN AND THE ORGANISATION OF NUCLEOLI IN PLANTS
}

\author{
L. F. LA COUR \\ John Innes Horticultural Institution, Bayfordbury, Hertford
}

Received I.ii.5o

\section{INTRODUCTION}

Low temperature treatment, with certain plant and animal species, allows a linear differentiation of somatic metaphase and anaphase chromosomes other than that which is characteristic at normal temperatures. Under the conditions of cold, heterochromatic parts become differentiated as segments of reduced diameter and, as shown with Feulgen, having a reduced nucleic acid charge (Darlington and La Cour, I940, I94I ; Geitler, I940 ; Callan, I942 ; Haga, I944; Haga and Kurabayashi, 1947, 1948). The chromomere-like differentiation obtained with special fixation methods by Shmargon (1938) in Secale and by Kakhidze (1939) in Crepis capillaris, has been compared with the differentiation produced by this nucleic acid starvation (Wilson and Boothroyd, 1944). There is, however, no resemblance either in the cause or in the effect.

The segments starved of nucleic acid at metaphase agree in number and position with the segments overcharged with nucleic acid in the resting stage. Both were therefore defined as heterochromatin in a strict sense by Darlington and La Cour (194I). It should be noted that Heitz (1928, I932) originally described heterochromatin as any part of the chromosome which was overstained during the resting stage. Since Heitz and others did not always use Feulgen staining some bodies may have been described by them as heterochromatin which were not overcharged with nucleic acid and therefore not heterochromatin in our stricter sense.

Contrary to our findings, Wilson and Boothroyd (1944) believe that revelation of the heterochromatic segments is dependent on a differential contraction of heterochromatin and euchromatin. Our microphotographs as well as camera lucida drawings, show clearly that this is not so. Such a view is also in conflict with that of Resende et al. (1944) who have shown in. Trillium sessile that the segments begin to differentiate at $9^{\circ} \mathrm{C}$. And moreover, that with supercontraction of the chromosomes which happens below $-6^{\circ} \mathrm{C}$., the differentiation of the segments is in no way modified.

However, these workers assume the segments to be either of nucleolar origin (which they clearly are not), or of an organisation intermediate between heterochromatin and nucleolar organiser (which 
is meaningless). The present observations will perhaps resolve these difficulties.

The scope of the present paper is primarily in the presentation of further studies on the mapping of heterochromatic segments in various plant species. These new observations substantiate the views we have previously held, views which in some cases conflict with the interpretation implied elsewhere (Kaufmann, I948; Vanderlyn, 1949). Those of a pertinent nature will also be discussed here.

\section{MATERIALS AND METHODS}

A large part of the Fritillaria material came from the Institution's collection. Root tips of a number of species were provided by Miss G. Beck of Great Amwell. For material of $F$. recurva and $F$. lanceolata I am indebted to Dr G. Mehlquist of Missouri Botanic Garden and bulbs of $F$. lusitanica to Prof. A. Fernandes of Coimbra University. The plant of Paris polyphylla like the earlier one, was from Edinburgh Botanic Garden. The Trillium species came from Messrs Perry of Enfield.

All the root tips were fixed in $2 \mathrm{BD}$ except those of Fritillaria where acetic alcohol $(\mathrm{I}: 3)$ proved more satisfactory. It gives with Feulgen staining, better definition of small intercalated segments. To minimise the occurrence of bubble artefacts, fixative was limited to I 5 minutes, hardening then being continued in 95 per cent. alcohol over-night. Following fixation, all the material was prepared as Feulgen squashes (Darlington and La Cour, 1947).

\section{THE SCOPE OF VARIATION}

\section{(i) Trillium}

The somatic complements of different species show little difference under normal conditions. With low temperature, however, species

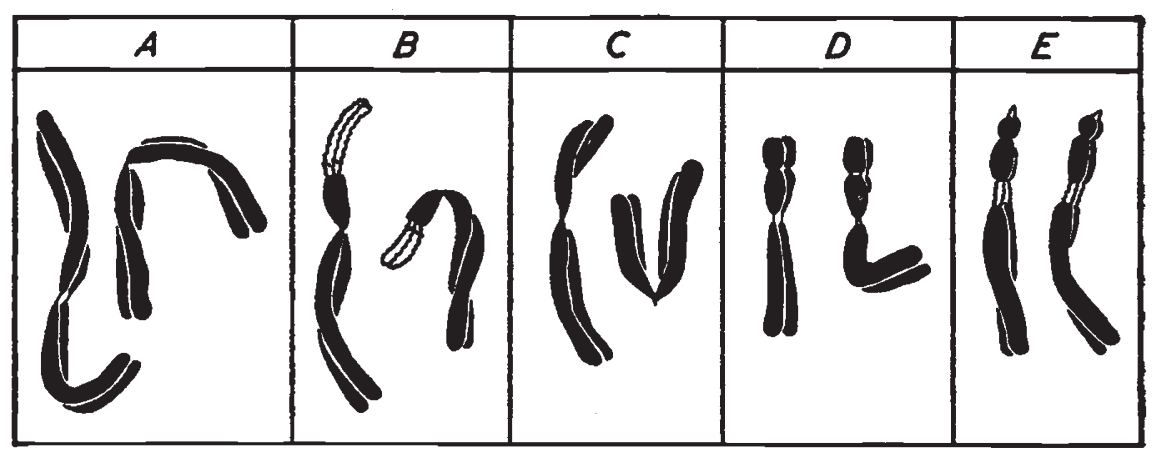

Fig. I.- Trillium erythrocarpum, heterochromatin revealed by cold treatment. Note B and possibly D are hybrid pairs. Both E's have a small trabant. $\times 1200$.

and indeed individuals differ significantly in the number, size and position of the heterochromatic segments. The same is true of 
chromosome mates within heterozygous individuals of Trillium species. In T. erythrocarpum a species indigenous to Eastern and North America and newly studied, only two pairs the B and D types, show a slight degree of heterozygosity (fig. I).

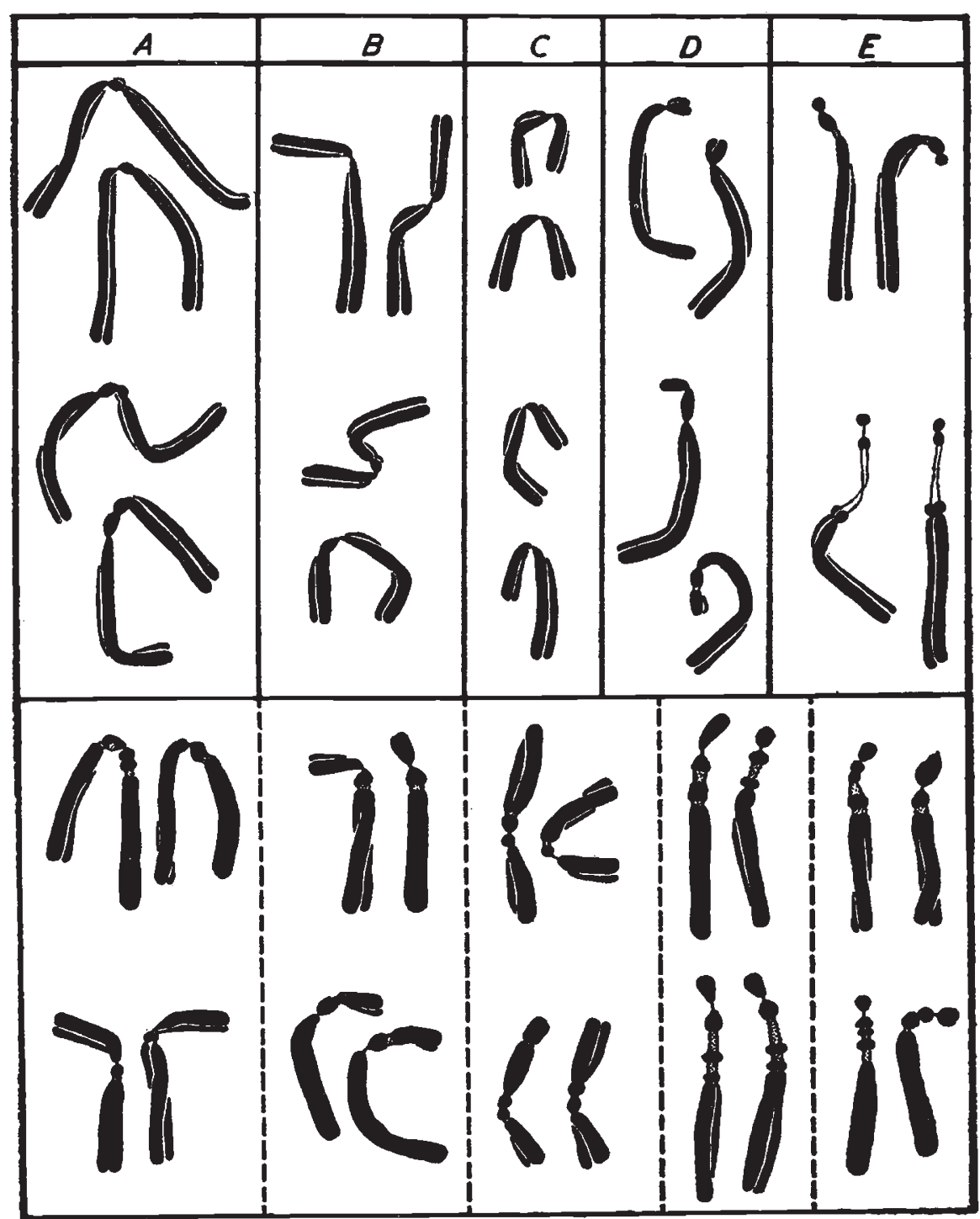

FIG. 2.-Trillium Tschonoskii above, $T$. apetalon below, with heterochromatin revealed by cold treatment. Centric constrictions represented as a single line, spiralised heterochromatin stippled. Note unspiralised heterochromatin in $2 \mathrm{E}$ chromosomes of $T$. $T$ schonoskii also trabant on an $\mathrm{E}$ chromosome of $T$. apetalon. $\quad \times 1200$.

Two tetraploid species, both of Asiatic origin, have been examined, namely $T$. Tschonoskii and $T$. apetalon $(T$. Smallii). Both are allotetraploids as is evident from their somatic complements ( $f f$. Haga, 
1934). Their complements differ from those of diploid Trillium, resembling rather that of Paris polyphylla and having 4 instead of 3 sub-terminal types. With cold treatment another difference from the diploid species becomes apparent. There are no terminal segments of heterochromatin. As a consequence, its total amount is visibly lower, especially in $T$. Tschonoskii where no segments are visible in any of the $4 \mathrm{C}$ types, in 3 of the $4 \mathrm{~B}$ types, or in 2 of the $4 \mathrm{D}$ types.

In this species also, 2 of the $\mathrm{E}$ chromosomes differ from the other two E's in having the heterochromatin uncoiled after cold treatment (fig. 2). The condition has been similarly figured in this species, following treatment with chloral hydrate (Haga, 1934). It was first described in the hexaploid Paris japonica.

\section{(ii) Paris polyphylla}

The new plant differs from the original clone in two respects. There is no fragment chromosome. Also the pattern of heterochromatin is slightly different. One of its A chromosomes contains a small intercalated euchromatic region. Both B's have gained an additional terminal heterochromatic segment. Whilst one of the C's has lost a terminal segment (fig. 3).

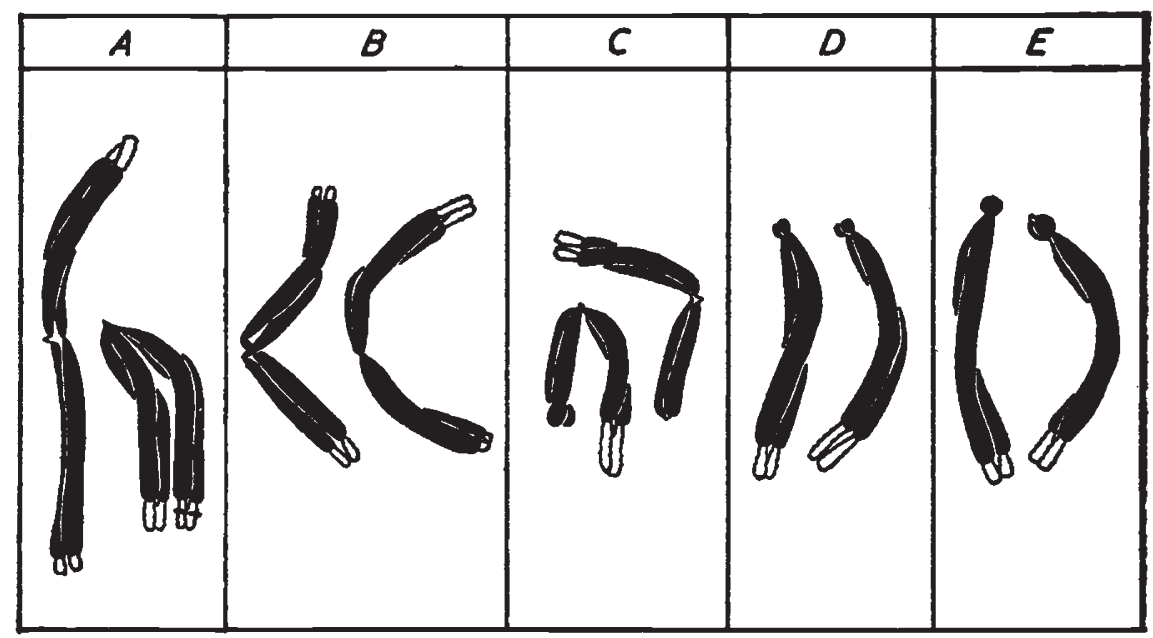

Frg. 3.-Paris polyphylla, heterochromatin revealed by cold treatment. All pairs show hybridity. A single $\mathrm{E}$ chromosome has a small trabant. $\times 1200$.

\section{(iii) Vicia faba}

So far as can be judged the segments are confined to positions near the centromere. They are also short, in fact shorter than the constrictions of nucleolar origin. Presumably some are also beyond the limits of resolution. For although up to 9 small chromocentres are detectable in the resting nuclei, 7 segments only are discernible at metaphase. It may be noted that in the readily distinguishable 
nucleolar chromosomes, the position of the starved heterochromatic segments is comparable to that of the chromocentres as figured by Heitz (1932).

In addition to nucleolar and heterochromatic (cold-starved) constrictions, there is a third type which appears irregularly in one

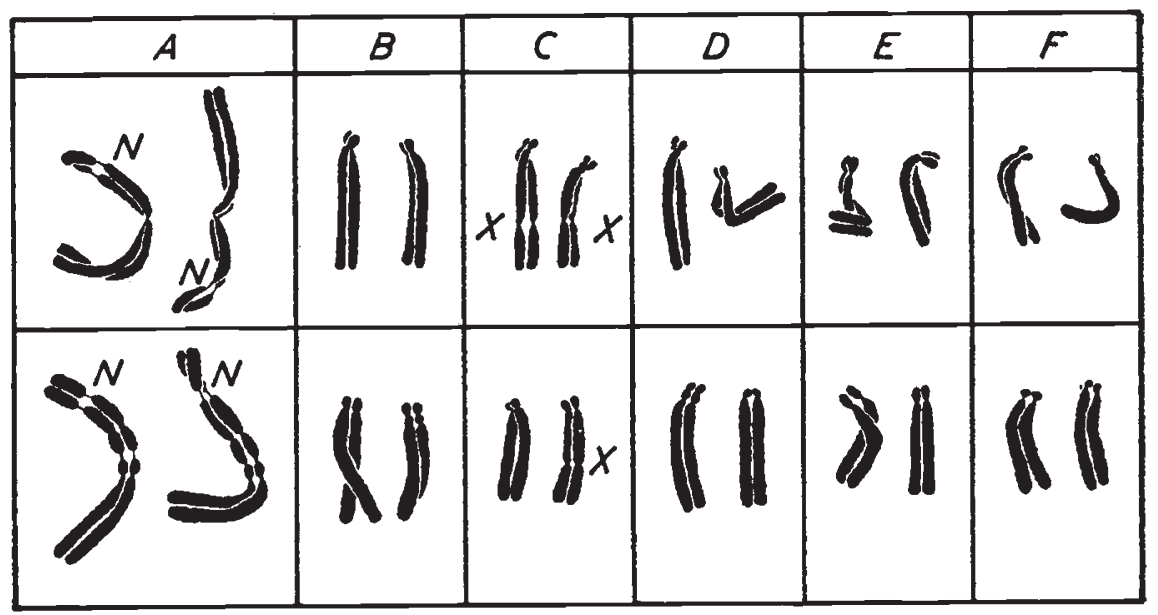

FIG. 4.-Vicia faba, above after normal temperature, below with heterochromatin as revealed by cold. There is difficulty in interpreting differences within pairs because of similarity in the types B-F. $\times 1370$.

short pair of chromosomes, equally at high and low temperatures but without any association with a nucleolus. This is labelled the $X$ segment (fig. 4).

\section{(iv) Fritillaria}

In our earlier account heterochromatin had been mapped only in $F$. pudica. From the evidence of chromocentres, 7 species out of 20 had heterochromatin ( $\mathrm{La}$ Cour, 1947). These included 4 out of 6 New World species. Moreover, these had far more heterochromatin than the 3 Old World species. The survey has since been continued employing the cold technique, wherever possible, in order to map the position of the heterochromatin. The results are given in table $\mathrm{I}$. It will be seen that out of 34 species examined, 12 out of 27 Old World species have detectable heterochromatin and similarly 5 out of 7 New World species. Again we still find the Old World species showing an appreciably lower content (fig. 5).

The heterochromatin has now been mapped in 7 species, 2 Iberian and 5 Californian. As well as in content, the 2 classes differ also in regard to the position and behaviour of the heterochromatin and, perhaps also in the position of the nucleolar organisers.

In the 2 Iberian species, $F$. lusitanica and $F$. pyrenaica, the heterochromatin is located mostly next to the centromeres. It leads to an apparent lengthening of the centric constrictions. This is true also 
L. F. LA COUR

TABLE I

(Darlington 1935, Beetle 1944, La Cour unpublished*)

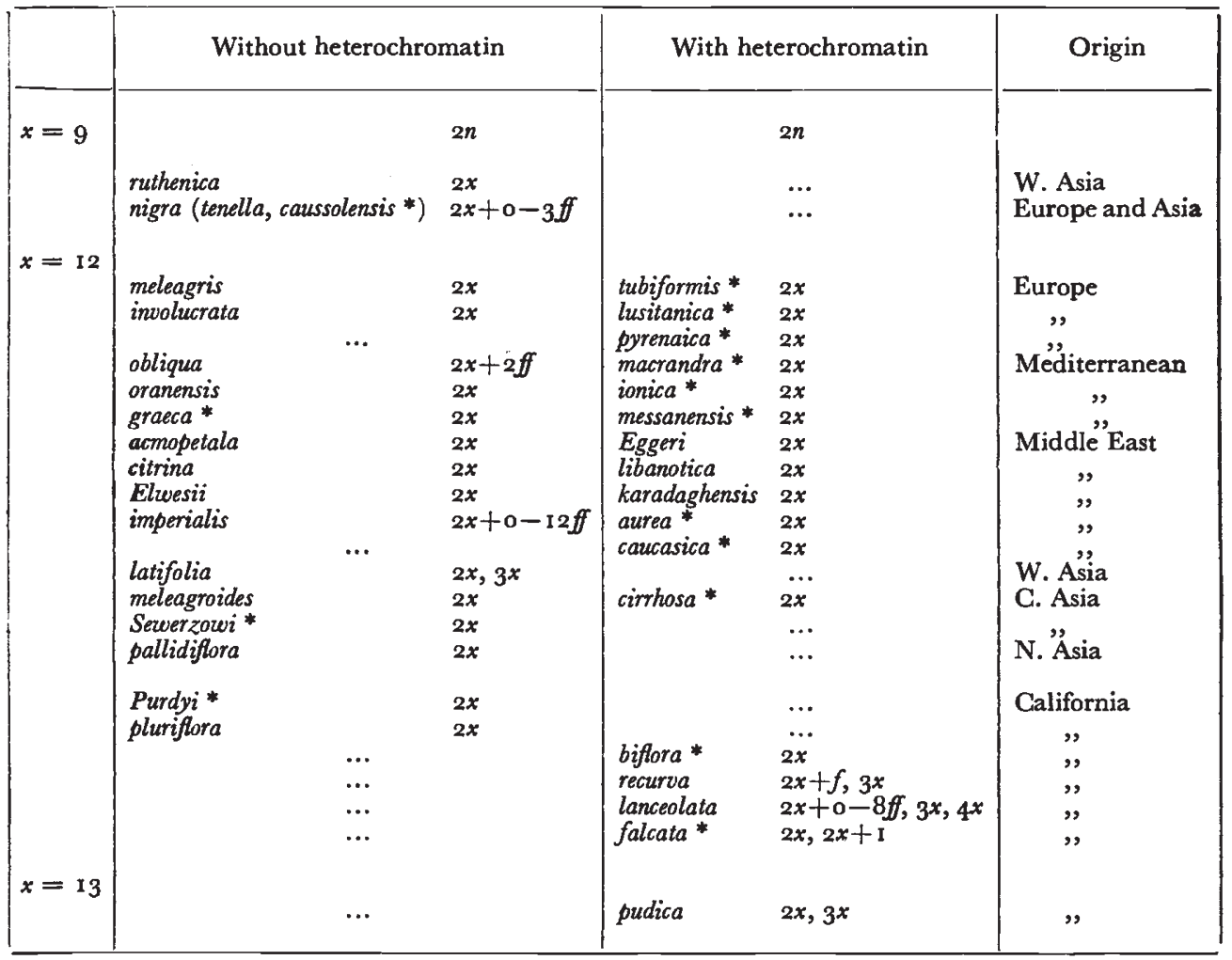

N.B. 一Botelho and Mendes (1944) were the first to describe heterochromatin in F. lusitanica. They claim counts of 26 chromosomes as in pudica.

SPECIES OF FRITILLARIA

OLD WORLD

NEW WORLD

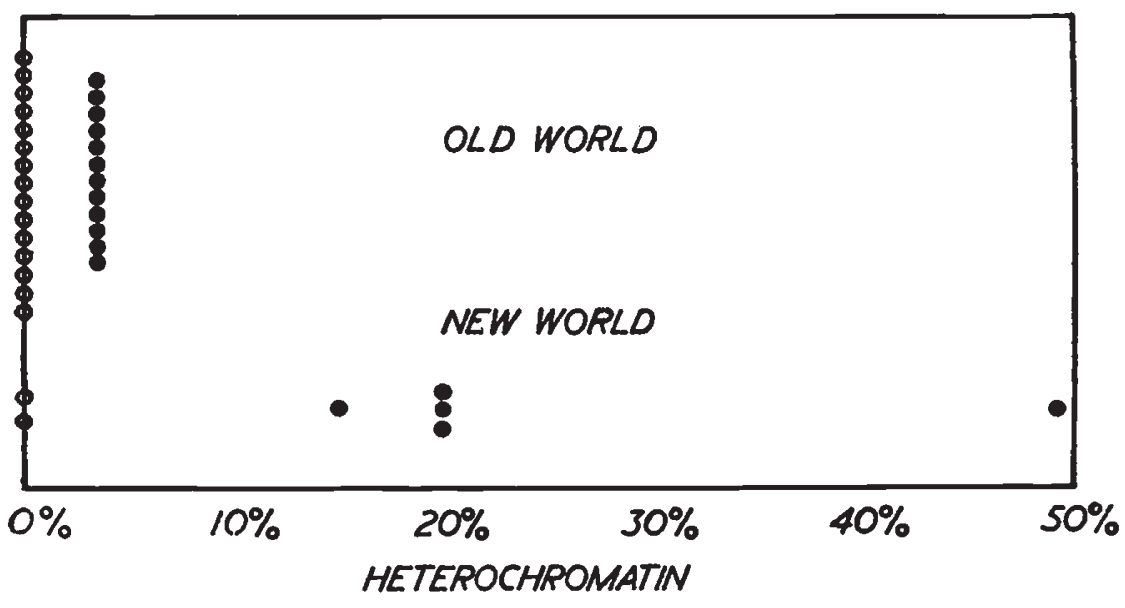

FIG. 5.-Graph illustrating approximate determination of heterochromatin content. Open rings denote absence of heterochromatin, closed rings with heterochromatin. Above, Old World, below, New World, species. 


$$
\text { 年 }
$$


even after normal temperatures, although the accentuation at these points may not always be so clearly defined. As an explanation for this behaviour I have suggested elsewhere ( $\mathrm{La}$ Cour, I950) that the abnormal nucleic acid cycle in the heterochromatin is exaggerated by the closeness of the centromeres which, we must remember also have an allocyclic behaviour.

Two of the Californian species, $F$. Purdyi and $F$. pluriflora have no heterochromatin. Two others, $F$. lanceolata and $F$. recurva have a pattern of heterochromatin comparable to that of $F$. pudica. It mostly lies near the centromere and amounts to about one-fifth of the whole. In a third, $F$. biflora, the position of the heterochromatin is similar, but in amount a little less. The last, $F$. falcata, on the other hand, would appear to be unique amongst all plants. Its euchromatin and heterochromatin are almost equal. Some of its chromosomes have short arms apparently devoid of all euchromatin. And, so far as can be judged, in some the centromeres are situated in a heterochromatic block (fig. 6). Owing to lack of root tip material, I have not as yet determined whether such regions have a similar behaviour to the centric heterochromatin in the Iberian species.

The only plant of this species I have examined contains 2 fragment chromosomes of unequal size. The plant is a fragmentation heterozygote with the chromosome number $2 n=25$. Presumably in its ancestry the fragments were derived from anaphase breakage of a dicentric chromosome formed at meiosis in a trisomic plant. Since triploid forms are not uncommon in the genus, possibly this may have arisen as a chance seedling from a triploid.

\section{(v) Scilla sibirica}

It has been found impossible to induce the metaphase cold-starved effect in this species. Heterochromatin is readily distinguishable in the resting nuclei. Between Io to 12 chromocentres are then seen.
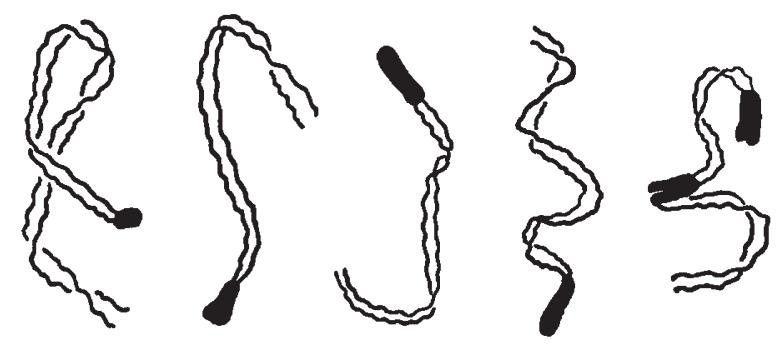

FIG. 7.-Scilla sibirica, selected chromosomes from a prophasic metaphase induced by beryllium nitrate. Euchromatin incompletely, heterochromatin completely, coiled. $\times 1850$.

It is also distinguishable and indeed located, in a fully charged condition, in the embryo sac at prophase of the four-cell stage. I am uncertain about all I2 chromosomes. Eight have a single distal 
segment. While two have besides a distal segment, another near the centromere.

Treatment with Beryllium nitrate $(0.02 \mathrm{~mol}$.) has also been tried. It produces an irregular starvation of the heterochromatin in Fritillaria (Darlington and La Cour, I947). Here, however, no such differentiation is obtained. On the other hand, the heterochromatin becomes distinguishable at metaphase in another way. A small proportion of the mitoses enter metaphase in a prophase condition. In contrast to the heterochromatin the euchromatin is incompletely coiled (fig. 7). A somewhat similar prophasic condition has been produced elsewhere by X-rays (Darlington and La Cour, 1945).

\section{NUCLEOLAR ORGANISATION}

In Fritillaria three types of nucleolar organisation may now be defined (i) most species have two chromosomes in each haploid set with a regular exclusive intercalary nucleolar organiser. (ii) In a few Old World species including the Iberian species, nucleoli arise irregularly on the ends of chromosomes as in Trillium, to give at metaphase chromosomes with small trabants. (iii) In $F$. lanceolata a regular intercalary and apparently irregular terminal kind of organisation occur together with an abundance of heterochromatin.

\section{NUCLEOLAR CONSTRICTIONS AND HETEROCHROMATIN}

It has been implied that the cold starved segments in Trillium are of nucleolar origin. There is no factual evidence in support of such a view. We have already shown that in Trillium the nucleoli arise on the chromosome ends to give at metaphase, in variable numbers, chromosomes with small trabants. The absence at normal temperatures of any regular secondary constrictions, we have considered to denote an absence of regular organisers. Moreover, the ends where the nucleoli arise do not show cold starvation or any other evidence of heterochromatin.

Then if we consider the evidence presented here. First, as we saw in Fritillaria some species have an irregular kind of nucleolar organisation comparable to that in Trillium. Then at low temperatures, in 5 American species of Fritillaria as well as in Vicia, nucleolar and heterochromatic constrictions coexist. The nucleolar kind are visible also at normal temperatures, the heterochromatic as a general rule are not. Moreover, in appearance the two kinds are unmistakably distinguishable from each other. With Feulgen, the nucleolar type presents a distinct gap in the chromosome arm, with the bridging thread unstained. The heterochromatic segments on the other hand, in favourable cells, show the coiling of the basic chromosome thread.

There are, however, examples of secondary constrictions difficult to define ( $c f$. Kaufmann, I948). No doubt as we have suggested 
(1940) some of these are heterochromatin. There is a similar difficulty as we saw in the interpretation of 2 small segments in a pair of chromosomes in Vicia. That they are equally visible at high, as at low temperatures, does not necessarily overrule them being heterochromatin. On the other hand, examination in more favourable tissues might show an alliance with a weak nucleolar organiser.

Klingstedt ( $194 \mathrm{I}$ ) has inferred that the nucleolar organiser is perhaps a special kind of heterochromatin. This has led ThermanSuomalainen (1949) to consider that certain unclassified constrictions could with equal justification be assigned to both groups. However, as pointed out by Darlington (1947) there is no necessary connection between nucleolar organisers and heterochromatin and there are very simple means of distinguishing them.

\section{THE COMPETITION FOR NUCLEIC ACID SUPPLY}

Low temperature allows us to locate the position of heterochromatic segments; seemingly because the genes in such regions suffer in competition from an inadequate supply (Darlington and La Cour, I940, 1941). There is little need of elaboration of the wealth of evidence in support of this view. It comes both from the similarity in natural occurring phenomena, such as occurs in sex chromosomes and from a wide variety of observations elsewhere (Callan, 1942; Levan, 1942 ; Wickbom, r945 ; La Cour, I944; Koller, 1946 ; Darlington and La Cour, 1945).

Not all heterochromatin, however, is influenced by treatment with cold. Such is the case with chromosomes known to be wholly heterochromatic, e.g. the supernumerary chromosomes in Narcissus juncifolius (Fernandes, 1939). Thus it may be surmised that the competition as such, is solely between chromosome parts and not between individual wholes. This is compatible with the fact that heterochromatin is typically located near the surface of the nuclear membrane. And may therefore perhaps be considered as liaison chromatin (Vanderlyn, I949).

However, even with heterochromatic parts of a readily detectable size, such as we find in Scilla sibirica, cold treatment may be ineffective. It fails here presumably because of an adaptation to growth at low temperatures. This would lead to a juxtaposition of the thresholds for mitosis and of the restriction of nucleolide supply.

Some idea of the adaptation of this species to cold conditions can be judged by experiment. Mitosis is normal at $-6^{\circ} \mathrm{C}$. after ro days, which is the coldest it has been possible to try. Also it is in no way affected by treatment at $-2^{\circ} \mathrm{C}$. for 2 months, which is the longest period tried.

\section{HETEROCHROMATIN AND SPECIATION}

The development of species in the genus Fritillaria is somewhat obscure in its evolution. Unlike that of so many other genera, 
hybridity and polyploidy appear to have played but minor roles. With the possible exception of $F$. phenanthera, presumed to be a natural hybrid between $F$. parviflora and $F$. recurva, species hybrids are apparently unknown to cultivation. As might be expected, allopolyploidy in the genus is unknown. Cytological evidence shows that some species have evolved through fusion and some by breakage of the chromosomes, e.g. $F$. ruthenica $n=9$ and $F$. pudica $n=\mathrm{I} 3$, as variations from the common basic haploid number $n=12$ (Darlington, 1937).

In view of the interesting differences in heterochromatin displayed by New and Old World species, the question naturally arises as to. what part heterochromatin has played in speciation and development of the evolutionary pattern. At the moment we are unable to wholly evaluate the possible imporiance of this relationship. For although it is generally assumed to be, we do not know if heterochromatin is present in the chromosomes of all plant and animal species. Neither do we know whether heterochromatin can arise from euchromatin or vice versa. However, two characteristic features are perhaps worthy of reminder.

In cold treated Trillium (Darlington and La Cour, 1940) it has been shown that at anaphase, undercharged heterochromatin is liable to errors in reproduction. Changes so induced may contribute to the development of the evolutionary pattern. Then must be considered the effects of polygenes providing smaller variation supplementary to that provided by major genes. Mather (1944) has shown them to be present, although not necessarily confined to, in heterochromatin. Thus it may be that the unparalleled and perplexing diversity of many American species, e.g. F. lanceolata (Beetle, 1944) is in part associated with the release of polygenic variation. For this species with an abundance of heterochromatin has moreover, unlike so many Old World species, free pairing and crossing-over at meiosis and hence the capacity for maximal recombination.

\section{THE ORIGIN OF HETEROCHROMATIN}

Heterochromatin is distinguishable from euchromatin by its allocycly, but it may be that the degree of dispersion determines whether such allocycly is detectable. Pontecorvo (I944) has attributed the allocyclic behaviour to the differentiation of groups of chromomeres with a similar nucleic acid cycle. He accordingly assumes that heterochromatic segments arise by repeated reduplication of minute euchromatic regions in juxtaposition. On such a view there is indeed scope for dispersal and elimination of old heterochromatic segments, as well as for the formation of new segments of variable size. The evidence in Fritillaria neither confutes nor confirms this view. Although here, with the means of vegetative reproduction and hence equipped for preservation of changes, we might perhaps. have expected greater variation in the pattern of heterochromatin. 
From various lines of work and thought it has emerged that heterochromatin plays an important physico-chemical role in the cell (Caspersson, I947 ; Darlington, I942, amongst others). Although the wideness of this role is perhaps somewhat conjectural ( $c f$. Vanderlyn, 1949). If such is indeed the case it would seem inconceivable that heterochromatin could ever be entirely absent from nuclei, at least of actively dividing cells. On such a view it would be assumed that the apparent absence of heterochromatin in some species of Fritillaria and, indeed in many species elsewhere, is indicative only of a finer degree of dispersion of the genes displaying heterochromatic behaviour. However, until this becomes an established fact one is tempted to present yet another point of view.

Let us assume that the chromosomes of all plant and animal species carry groups of replicated genes of a low order of specificity such as would on Mather's view be described as polygenes. These may have the same functions in the cell as those attributed to recognisable heterochromatin without showing its visible properties, which we may surmise are under genotypic control.

\section{SUMMARY}

I. Of 34 species of Fritillaria studied, half have no detectable heterochromatin. All but 2 of 7 Californian species have heterochromatin and, moreover, considerably in excess of any Old World species examined.

2. In $F$. falcata, a Californian species, the content of heterochromatin and euchromatin is almost equal. The individual examined was found to be a fragmentation heterozygote with the chromosome number $2 n=25$.

3. The Iberian species, $F$. pyrenaica and $F$. lusitanica have compound centric constrictions due to heterochromatin lying next to the centromere. It leads to a lengthening of the constriction which is equally clear at high and at low temperatures.

4. Tetraploid species of Trillium and Paris have less heterochromatin than diploids.

5. In tetraploid Trillium Tschonoskii, 2 of the $4 \mathrm{E}$ chromosomes are heterozygous in respect of showing the heterochromatin in an unspiralised condition.

6. Adaptation to growth at low temperatures such as is found with Scilla sibirica inhibits cold-starvation of the heterochromatin at metaphase.

7. Problems relative to interpretation, origin and role of heterochromatin in evolution are discussed.

Acknowledgment.-Thanks are due to Dr C. D. Darlington, F.R.S., for advice and criticism. 


\section{REFERENCES}

CALlan, H. G. 1942. Heterochromatin in Triton. P.R.S., B, 130, 324-335.

BEETLE, D. F. I944. A monograph of the North American species of Fritillaria Madron̂o, 7, I33-159.

воTELHO, M., AND MENDES, E. J. 1946. Caryological studies on Fritillaria lusitanica. Portugaliae Acta Biol., I, 3 1 0-312.

CASPERSSON, T. 1947. The relations between nucleic acid and protein synthesis. Sym. Soc. Exp. Biol., I, 127-151.

DARLington, C. D. 1937. Recent Advances in Cytology. 2nd ed. London : Churchill.

Darlington, C. D. 1942. Chromosome chemistry and gene action. Nature, I49, $66-69$.

Darlington, c. D. 1947. Nucleic acid and the chromosomes. Symp. Soc. Exp. Biol., I, 252-269.

DARLington, C. D., AND LA COUR, L. F. 1938. Differential reactivity of the chromosomes. Ann. Bot., 2, 61 5-625.

DARLINGTON, G. D., AND LA COUR, L. F. 1940. Nucleic acid starvation of chromo* somes in Trillium. 7. Genet., 40, 185-2 13.

DARLINGTON, C. D., AND LA COUR, L. F. 1941. The detection of inert genes. $\mathcal{f}$. Hered., 32, 1 1 5-1 21 .

DARLington, C. D., AND LA COUR, L. F. 1945. Chromosome breakage and the nucleic acid cycle. F. Genet., 46, $180-267$.

DARLington, c. D., AND LA COUR, L. F. 1947. The Handling of Chromosomes. 2nd ed. London: Allen and Unwin.

DARlington, C. D., AND LA COUR, L. F. 1950. Hybridity selection in Campanula. Appendix by the author, Compound constrictions. Heredity 4, 21 7-248.

FERNANDES, A. 1939. Sur le comportement d'un chromosome surnuméraire pendant la mitose. Sci. Genet., I, 141-167.

GEITLER, L. 1940. Temperaturbedingte Ausbildung von Spezialsegmenten an Chromosomenenden. Chromosoma, I, 554-561.

HAGA, T. 1934. The comparative morphology of the chromosome complement in the tribe Parideae. F. Fac. Sci. Hokkaido Univ., 3, 1-32.

HAGA, T. 1944. Morphological reaction of chromosomes to low temperature. Fap. F. Genet., $20,87$.

hagA, T., AND KURABAYASHI, M. 1947. Genome analysis in the genus Trillium on the basis of differential reaction of the chromosomes. Fap. F. Genet., $22,8$.

hagA, T., AND KURABayashi, м. 1948. Chromosomal variation in Trillium kamtschaticum. Fap. F. Genet., $23,12$.

HErTz, E. 1928. Das Heterochromatin der Moose. I. Jahrb. f. wissensch. Bot., $69,762-818$.

hertz, E. 1932. Die Herkunft der Chromocentren. Planat, 18, 571-635.

KAKHIDZE, N. T. 1939. Some structural details of Crepis capillaris chromosomes. C.R.A.S. URSS., $26,468-470$.

KaUfmanN, B. P. K. 1948. Chromosome structure in relation to the chromosome cycle II. Bot. Rev., 14, 57-126.

KLINGSTEDT, H. I94I. Negative heterochromacy in Orthopteran chromosomes. Mem. Soc. Faun. Flor. Fenn, 17, I66-1 75 .

Koller, P. C. 1946. Control of nucleic charge on the X-chromosome of the hamster. P.R.S., B, 133, 31 3-326.

LA COUR, L. F. 1944. Mitosis and cell differentiation in the blood. P.R.S. Edin., B, $62,73-85$.

LEVAN, A. 1942. Studies on the meiotic mechanism of haploid rye. Hereditas, 28, I 77-2II.

MATHER, K. 1944. The genetical activity of heterochromatin. P.R.S., B, 132, 308-332. 
PONTECORVO, G. 1944. Structure of heterochromatin. Nature, 153, 365-372.

SHMARGON, E. N. 1938. Analysis of the chromomere structure of mitotic chromosomes in rye. C.R.A.S. URSS, $2 I, 259-262$.

THERMAN-SUOMALAINEN, E. 1949. Investigations on secondary constrictions in Polygonatum. Hereditas, 35, 86-1 08.

VANDERLYN, L. 1949. The heterochromatin problem in cyto-genetics as related to other branches of investigation. Bot. Rev., 15, 507-582.

шісквом, т. 1945. Cytological studies in Dipnoi, Urodela, Anura and Emys. Hereditas, $31,241-346$.

WILSON, G. B., AND BOOTHROYD, E. R. 1944. Temperature-induced differential contraction in the somatic chromosomes of Trillium erectum L. Canad. F. Res., 22, $105-119$. 